\title{
Vida nova para o Jornal Brasileiro de Patologia
}

Finda a minha atual gestão junto à Diretoria Científica da Sociedade Brasileira de Patologia Clínica e Medicina Laboratorial (SBPC/ML), este é o último editorial que escrevo para o Jornal Brasileiro de Patologia Clínica e Medicina Laboratorial (JBPML). Foram ricos momentos em que me sentei diante de uma página vazia do Word e que, pensando em você, meu interlocutor, buscava estabelecer uma troca de idéias imaginária a respeito da atividade de laboratório clínico no Brasil.

Como não sou pesquisadora, não pude, com certeza, estabelecer um diálogo mais pertinente com aqueles que publicam em nossas páginas. Portanto hoje me dirijo especificamente a vocês, cientistas, aos quais quero agradecer, em meu nome e em nome de todo o corpo editorial, o esforço empreendido para publicarem em nossas páginas.

Nesta rica experiência pude acompanhar o trabalho do nosso editor-chefe, o Dr. Octavio Fernandes, em busca de nossa meta de produzir um jornal de padrão científico internacional. O Dr. Octavio também se despede de suas funções, e eu não poderia deixar de fazer o elogio ao seu brilhantismo e à sua dedicação. Ele deixa marcas profundas no JBPML, hoje indexado junto ao SCIELO e com avaliação A pelo Qualis sob a rubrica Conteúdo Médico.

E vem gente nova aí. O Dr. Carlos Alberto Franco Ballarati assume a posição de diretor científico para o próximo período, com a pesada responsabilidade de escolher um novo editor-chefe e de manter a trajetória de qualidade do JBPML. Assume também a árdua tarefa de perseguir nossa meta de indexação no Index Medicus. Para que a consigamos, faço meu apelo final a vocês, autores do JBPML: ajudem-nos continuando a prestigiar nosso jornal para a publicação de papers e artigos originais relevantes para a Patologia Clínica e para a Anatomia Patológica. Colaborem também na sua divulgação aos seus pares. De nossa parte, a SBPC/ML, a Sociedade Brasileira de Patologia (SBP) e a Sociedade Brasileira de Citopatologia (SBC) continuarão a envidar seus melhores esforços para que o Jornal Brasileiro de Patologia continue exercendo seu fundamental papel de divulgar a ciência brasileira. 